Inclusive Leadership and Social Justice for Schools

James Ryan

Ontario Institute for Studies in Education of the University of Toronto, Canada

(Published in Leadership and Policy in Schools (2006), 5 (1) 3-17.)

This article sketches out a framework for inclusive leadership. As one of the constellation approaches to leadership and social justice, inclusive leadership is concerned first and foremost with inclusion, both in its processes and the ends for which it strives. It provides another lens to help those concerned with social justice recognize social injustice in communities and schools and do something about it. The article is organized in the following manner. First, the concept of leadership and social justice are introduced. Next, I explore the relationship between social justice and inclusion. This is followed by an account of inclusion and leadership. Finally, I describe inclusive leadership practices.

\title{
Leadership and Social Justice
}

For some time now the idea and practice of leadership has figured prominently in efforts to improve schools. Initially, educators borrowed their models of leadership from management studies. In doing so, they promoted and adapted organizational arrangements that invested particular individuals with power so that the latter would be able to force, motivate or inspire others in ways that would help schools achieve the comparatively narrow ends of efficiency and productivity (Blackmore, 1999; Ryan, 1988; 1991). Recently, however, this approach has increasingly come under fire. Challengers have contested the hierarchical relationships that dominate such organizations and pointed to the limitations of a leadership model that does not look beyond narrowly defined organizational goals (Blackmore, 1999; Marshall, 2004; Ryan, 2006). These scholars and educators emphasize that leadership in schools needs to be about deeper moral purposes like social justice because they believe that schools must do their part in contributing to a world that is fair for everyone. 
Educators have had good reason to be concerned with social justice. As diversity has become more apparent in our schools and communities, the divisions that separate the advantaged from the disadvantaged have also widened. Not everyone does well in our educational institutions and not everyone is equally advantaged in our communities. This inequality does not happen randomly or by happenstance; rather, it displays distinct patterns. These patterns revolve around markers of distinction consistently associated with ethnicity, race, social class, gender, sexual orientation, mental and physical ability, language and so on. Students from poor families (Coleman et. al., 1966; Jencks, 1972; Natriello et. al, 1990), with a few exceptions, those who are not of Anglo/European heritage or White (Bennett, 2001; Ogbu, 1994; Paquette, 1990), and gay and lesbian students (Shapiro, Sewell, Ducette, 2001; Sears, 1993) do not do as well as their counterparts in school. Furthermore, they are more likely to drop out of school before graduation, and less likely to go on to post-secondary education. Those who do pursue education beyond the secondary level generally attend vocational institutions or colleges and take two-year programs. Gender also continues to be a concern. While girls and women are doing reasonably well in some areas like language arts, they still lag behind their male counterparts in other areas, like science (Education Quality and Accountability Office, 2002; Organization for Economic Cooperation and Development, 2005). Moreover, girls and women, and non-white, and gay and lesbian students and educators continue to experience others forms of harassment, sexism, racism and homophobia in schools that prevent them from taking advantage of what schools have to offer (Datnow, 1998; Lugg, 2003; Orenstein, 2002; Stein, 2002). 
Alarmed by these glaring and persistent disparities and dissatisfied with traditional management approaches that do little to acknowledge or address these injustices, those interested in leadership have begun to search out and develop other models. These models are concerned first and foremost with social justice - searching out, understanding, critiquing and doing something about injustices. Even at this early stage, a number of various approaches consistent with social justice have emerged. They include, among others, critical race (Lopez, 2003, Taylor, this edition), transformative (Brown, 2004), critical ecological (Furman \& Gruenewald, 2004), feminist (Blackmore, 1999; Grogan, 2002), communitarian (Shields, 2003), pragmatically prophetic (Dantley, 2005), culturally responsive (Johnson, this edition), biographical (Jansen, this edition) and democratic (Moller, this edition, Woods, 2005) perspectives on leadership. Each provides its own unique insights and each can play its own role in overturning the injustices that occur in schools and communities. My purpose in this article is to introduce another approach to leadership and social justice - inclusive leadership. My hope is that it will make sense to those who read it, provide them with new ways to understand and critique injustice, and move them to do something about it.

\section{Social Justice and Inclusion}

Social justice is not an easy concept to define. There are many reasons for this. One is that there are many versions of it. Another reason is that some versions contain their own ambiguities and contradictions. A third reason is that many approaches are simply unpractical (Corson, 1993). Most commentators on social justice, though, concede that it is about legitimacy, fairness and welfare. One of the most well known writers in the area, Rawls (1972), circulates the idea that social justice requires the fair distribution 
of goods. He contends that social justice will be achieved when goods, rights and responsibilities are equally distributed among individuals. While Rawl's distribution ideal has its merits, it also has limitations. The most obvious is its individualistic emphasis on distribution. Rawls is preoccupied first and foremost with how goods are distributed to individuals and whether or not each is receiving his or her due. However, this individualistic focus tends to deflect attention away from the patterned relationships - the structures or forms - through which this distribution occurs (Corson, 1993; Gewirtz, 2002; Young, 1999). This is a problem because the root of unequal distribution lies not with the distribution itself or exclusively with the individuals who are part of this process, but with the formal and informal rules or norms that govern how members of society treat one another. Thus, enduring changes to the way distribution occurs will require alterations in the structured ways in which people relate to another within social institutions and forms of life.

Social justice can be seen in a number of ways. One is in terms of inclusion. Those who promote inclusion believe that social justice can be achieved if people are meaningfully included in institutional practices and processes. Efforts to use inclusion/exclusion as a lens for addressing social justice issues are well underway in studies of poverty in Europe and attempts to understand and do something about the plight of differently-abled students in schools. The idea of inclusion has been part of education for some time now, generally associated with the education of "special needs," "exceptional" or "differently-abled" students (Bailey \& du Plessis, 1997; Keys, HanleyMaxwell, \& Capper, 1999). Researchers and educators have used the term inclusion to illustrate the effects of exclusion and inclusion on these students, and to advocate for 
their inclusion in mainstream classes. More recently, other scholars have expanded the notion of exclusion and inclusion beyond the differently-abled to encompass other axes of dis/advantage such as age, race, class and gender (Boscardin \& Jacobsen, 1997, Dei, James, Karumancherry, James-Wilson, Zine, 2002; Riley \& Rustique-Forrester, 2002). Their basic premise is that students can be excluded not just from the school premises, but also from learning processes and activities because of ability, age, race, class, gender and sexuality. These studies are important because they draw attention to exclusion and inclusion in education and help us understand the ways in which students are excluded, the patterns that this process follows, and the benefits that accompany inclusion. The point that these scholars make is that social justice cannot be achieved when students (and their parents) are excluded from key educational processes.

Researchers studying poverty in Europe have also used the terms inclusion and exclusion (Mandipour, Cars, \& Allen, 1998; Byrne, 1999; Munck, 2005). They prefer to see social injustice not just in terms of poverty, but also as a multi-dimensional process in which various forms of exclusion are combined. Among other things, they are interested in the extent to which men, women and children have access to current social, economic, political or cultural systems - to participation in decision-making and political processes, to employment and material resources, and to integration in common cultural processes like education (Walker \& Walker, 1997; Mandipour et. al., 1998). In this view, people are excluded when they lack the resources to obtain certain types of diet, to participate in various activities and to enjoy the living conditions and amenities that are customary. The advantage of this approach is that it avoids blaming individuals, emphasizing instead the relational and structural nature of their misfortunes. Advocates of this approach 
contend that structural processes rather than individuals and groups systemically create barriers and inequalities that prevent the social advancement of the poor, disempowered and oppressed and ultimately inhibit the fair distribution of goods. Social justice will be achieved, then, only when changes to the system allow for meaningful inclusion of everyone, particularly those who are consistently disadvantaged or marginalized.

These two approaches complement one another and provide a useful framework for understanding and doing something about injustices in schools and communities. First and most important, they shift blame away from individuals, and in doing so, clear the way for uncovering the often taken-for-granted role of institutions and systems in shaping the unequal way people relate to one another, and the resulting unjust distribution of goods, rights and responsibilities. They also allow us to explore the particular forms and patterns that injustice follows in communities and schools. Perhaps the most attractive feature of viewing social justice in terms of inclusion, though, is its positive focus. While it does highlight the negative and unjust side of life - enabling us to see exclusion for what it is - it also provides us with a sensible and practical alternative inclusion. The goal of inclusion is to see that everyone is included in the social processes common to communities and schools. This practical target gives us something to work towards and, when achieved, will go a long way in making the world a more just place. In working toward this goal, however, we need to be careful about how we approach inclusion (Munck, 2005). This is because inclusion can easily be seen in unhelpful ways. Conservative proponents, for example, believe that inclusion is simply a matter of integrating the excluded, marginalized and problematic into an already existing system. This system, however, is "good", "clean" and unreservedly "white", middle class, male 
and heterosexual. The task for them, then, becomes a social engineering one. People are to be included, that is integrated, so that the system can continue to run smoothly without unnecessary conflicts or any fundamental changes. The status quo persists, with new participants, without any significant changes to the system.

The problem with this conservative view of inclusion is that it does not permit the marginalized to participate because they will not have the resources, tools or skills to do so, or the means to acquire them. Meaningful inclusion, then, requires that the system change. Inclusion involves more than engineering minor problems; it can only be achieved when the structural and inherent features of an already unequal system are changed. Doing this means not only permitting access for all, but also allowing the accessed to shape systemic practices so that they will be able to contribute and benefit from them just like everyone else. The marginalized must be empowered so that they will be able to gain confidence and develop skills to control their participation, contributions, and ultimately, their own lives. Participants need to see this as an active process where change is generated not from "without" but from "within" (Munck, 2005). Everyone will be included in school and community life only when the system changes and this change will best be achieved with contributions from everyone.

Leadership arrangements provide us with one set of strategies for working toward inclusion. Not all leadership approaches are up to this task, however.

\section{Leadership and Inclusion}

Leadership and social justice are not natural bedfellows; nor are leadership and inclusion. The extent to which leadership meshes with social justice or inclusion depends on the way in which leadership is conceived, that is, in the way that relationships are 
envisioned among members of institutions, in the roles that are prescribed for individuals and groups, and in the ends to which leadership activities are directed. More traditional concepts and practices of leadership are generally not consistent with inclusion. Longstanding management-oriented views of leadership, for example, exclude members of organizations in the hierarchical relationships that they promote between managers and others, in the way in which they invest leadership power with individuals in particular positions, and in the way in which they promote efficiency and productivity at the expense of more specific ends, such as social justice or inclusion (Blackmore, 1999; Marshall, 2004). In this view, those who are not in management positions will be excluded from decision-making processes because they supposedly do not merit this inclusion. Vesting the power that comes from formal leadership in single individuals also excludes others who are not in these positions. Finally, the values of efficiency and productivity do little to promote the cause of inclusion if leadership activities do not specifically target the latter.

There are a number of approaches or elements of approaches to leadership that are consistent with inclusion. They provide a useful roadmap for developing and promoting the concept and practice of inclusive leadership. Most importantly, they illustrate how leadership can operate within equitable, horizontal relationships, and as a collective process that is organized specifically to strive for inclusion.

A number of inclusive-friendly leadership theories reject hierarchical views of leadership. Advocates distrust the hierarchies that accompany bureaucratic forms of organization. They correctly point out that these kinds of arrangements both reflect and reinforce wider social hierarchies and injustices (Corson, 1996). Some contend that these 
organizational hierarchies themselves display class and gender overtones (Blackmore, 1989; Grace, 1995). Feminists have been the most articulate about this. They have argued that this hierarchical division of labor is masculine in nature, and they criticize the ideals of power and control that are part of this corporate management view (Blackmore, 1999; Grundy, 1993; Ozga, 1993). The point is that hierarchies are not consistent with inclusion. They exclude those not privileged enough to occupy formal positions of authority and those who do not possess the personal characteristics needed to influence others. For leadership to be genuinely inclusive, it must foster equitable and horizontal relationships that also transcend wider gender, race and class divisions.

Many of the approaches to leadership cited above favor more collective forms of leadership over individual ones. Some of these views acknowledge that concentrating leadership power in a single individual is exclusive; those who are not considered leaders are left out of leadership-related activities (Foster, 1989; Ryan, 2003; 2006). Go-it-alone individuals also leave problems in their wake when they move on to other positions (Hargreaves, In Press). Others make the point that the influence of single individuals on institutions is generally limited, and as a consequence, it does not make sense to rely so heavily on single leaders. One of the more insightful of these approaches is called distributed leadership (Gronn, 2002; Pounder, Ogawa, \& Adams, 1995; Spillane \& Orlina, 2005). It suggests that there is a difference in the way some scholars think about leadership and what actually happens in schools and other organizations (Gronn, 2002; Smylie, Conley, \& Marks, 2002). Research into teacher leadership, for example, has revealed that leadership is not simply a function of an individual leader's ability, knowledge, charisma and cognition, but part of a socio-cultural context. In other words, 
influence is more than the product of an individual's actions. It is best understood as a distributed or organizational practice that is "stretched over" varieties of artifacts, tools, language, people and relationships (Spillane et. al., 2005). Debunking the heroic view of leadership, these and other scholars point out that individual men and women who occupy formal positions are seldom capable on their own of creating fundamental changes. As a consequence, they call not for heroes, but for modest men and women to step forward (Foster, 1989). Schools improve not necessarily as the result of individual people doing remarkable things in isolation, but from a variety of people working together in many different ways and roles, using the multitude of different resources that are available to them (Leithwood, Jantzi, \& Steinbach, 1999; Smylie et. al., 2002). Leadership is best seen not in terms of individuals but as a collective process.

A number of these inclusive-minded approaches also emphasize the importance of clearly specifying the ends for which leadership should be directed, which in this case is also inclusion. Emancipatory leadership approaches and leadership for the differentlyabled are the most helpful in this area. Proponents of emancipatory approaches are first and foremost concerned with social justice (Foster, 1989; Marshall, 2004). They believe that leadership activities need to be organized to pursue these ends on both a local and global scale, and they view leadership processes as only one element of this enterprise. The task for leadership is to get people to recognize these injustices and work together to change them. Those who work in the area of leadership for the differently-abled provide a more focused goal (Keys et. al., 1999). They unabashedly advocate for the inclusion of differently-abled students in mainstream classrooms and they see leadership as one way of achieving this end. It is important to recognize that there is little point for the processes 
of leadership to be inclusive, if the entire leadership enterprise is not also organized to pursue inclusion in schools and communities. For leadership to be consistent with inclusive ideals, then, it needs to be seen and practiced as an equitable, collective process that is also organized to promote inclusion.

The Practice of Inclusive Leadership

Inclusive leadership consists of a number of distinct practices. They include advocating for inclusion, educating participants, developing critical consciousness, nurturing dialogue, emphasizing student learning and classroom practice, adopting inclusive decision- and policy-making strategies, and incorporating whole school approaches.

If leadership processes are to be inclusive they need to be organized to advocate for inclusion. This is because advocacy can counteract commonplace resistance to inclusive ideas and practices. Teachers and administrators are often opposed to the inclusion of differently-abled students in mainstream education (Bailey \& Du Plessis, 1997; Ingram, Mayerowetz, \& Weinstein, 1999). But resistance to inclusion extends far beyond this issue. Research indicates that administrators are reluctant to admit to the presence of racism in their schools (Ryan, 2003), just as some teachers condone sexism (Datnow, 1998). Some of these exclusive views and practices are obvious, as in the case of racial prejudice; others are subtler and find expression in testing and tracking practices. In order to counter these tendencies, those involved in leadership practices in schools can establish alliances with like-minded others (Bishop, 2002), make inclusion nonnegotiable (Keys et. al., 1999) create cognitive dissonance, discomfort and a sense of urgency among members of the school community (Thousand \& Villa, 1994). They may 
also share with others the theoretical, ethical and research-based rationales for inclusive education and leadership (Thousand \& Villa, 1994); trade and bargain with resistors (Gale \& Densmore, 2003); stall and maneuver to counter exclusive policies (Gale \& Densmore, 2003); establish links between educators and disadvantaged groups (Oakes \& Lipton, 2002); and involve school and community stakeholder groups in formulating objectives for supporting all students (Thousand \& Villa, 1994).

Inclusive leadership is educative (Evans, 1999; Smyth, 1989). Educating the whole school community about inclusive issues is important because administrators, teachers, students and parents, particularly those in more diverse settings, generally know too little about each other, about exclusive practices such as racism and how to approach and implement inclusive practices (Ryan, 2003). If everyone is to meet the challenges associated with inclusion, then they will have to acquire new knowledge, understandings and attitudes. To do so, all members of the school community have to assume the role of both teacher and learner. Educators must help parents and students learn about the school system and community and about existing opportunities. Parents also need to help educators learn about themselves and their communities. This can be accomplished in both informal and formal ways -- in the day-to-day interactions among members of the school community and in more structured ways. For educators, the formally organized developmental activities that work best are directly related to their practice and sustained over longer periods of time. Parents can be informed through newsletters, brochures, handbooks, formally and informally organized meetings and face-to-face interaction. Both can benefit from sustained and systematic efforts associated with programs like organizational learning (Senge, 1990). With regards to sensitive matters such as racism, 
schools need to find a balance that maintains pressure to be reflective about current assumptions and practices, without being confrontational in a way that merely reproduces and amplifies current conflicts. The best route to take is one that is positive without being comfortable and that prompts people not only to reflect on the present state of affairs, but also one that doesn't produce the fear and guilt that trigger further conflict. This strategy recognizes that people make mistakes, and that these mistakes should be acknowledged and discussed in a constructive manner (Gillborn, 1995).

Educating the whole school community is important. Also vital, though, is the kind of education in which administrators, teachers, students and parents participate. For inclusion to become a normal part of school practices, this education needs to be first and foremost critical. To achieve this end, school communities need to develop in their members a critical consciousness (Anderson, 1990; Blasé \& Anderson, 1995; Foster, 1989; Grundy, 1993). In order for individuals to break out of their usual patterns of thinking that obscure exclusion, they need to engage others - particularly different others - in critical conversations. These critical conversations can help school communities acknowledge, recognize, critique and change those invisible practices that impede inclusion. School communities can do a number of things to promote these critical conversations. They can first provide an atmosphere that supports them. It will be easier for everyone to look critically at school and community practices if it is the norm, that is, part of the culture of the school. Members of the school community can also engage in a number of activities designed to help critical reflection. These include testing out platforms, modeling, cognitive apprenticeships, administrative portfolios, journals, case records and studies, two column analyses, various scenario analyses and simulations and 
value audits (Coombs, 2002). School communities can also structure critical conversations around sets of questions. Some of these questions might include: What is happening here? What do we know about this? Who says this is the way things should be? What overall purposes are being served? Whose vision is it? Whose interests are being served? Whose needs are being met? Whose voices are being silenced, excluded, or denied? How come some viewpoints always get heard? Why is this particular initiative occurring now? What kind of prudent and feasible action can we adopt? Who can we enlist to support us? How can we start now? How are we going to know when we make a difference? (Smyth,1996).

For school communities to promote critical consciousness and inclusive communities, they need to nurture dialogue (Maxcy, 1998; Ryan, 2003; Shields, 2003; Smyth, 1989). In order for everyone to be meaningfully included, schools need to provide opportunities for people to be able to communicate effectively with one another. For these dialogues to succeed, however, participants need to have an emotional investment in them; they have to want to participate in dialogues (Burbules, 1993). It will be easier for people to do this when they are able to trust others. Where there is an element of risk, participants have to know that they can rely on someone or something. Besides trust, other feelings like respect, appreciation, affection and hope can play an important part in broadening and extending dialogues. It is also important to ensure that everyone has a voice. For this to happen, everyone must have an equal opportunity to speak, to respect other members' right to speak out and to feel safe to talk; all ideas must be tolerated and subjected to fair assessment (Burbules, 1993). On occasions where dominant and non-dominant individuals and groups are engaged in dialogue, it is 
important for listeners from dominant groups to provide as much comfort as possible so that the latter can speak their minds (Levine-Rasky, 1993). In these circumstances, it helps to displace oneself as knower and evaluator, abandon a desire to overtly assign a relative worth to observations, reflect on one's privileges, suspend personal authority, be willing to experience vulnerability, and to admit one's ignorance. Dialogue can also be nurtured when educators position themselves in ways that bring them into contact with others. They can do this by spending time on the phone for positive reasons, making themselves available at all times, hanging around areas that colleagues, students and parents frequent, going out in the community to meet and visit with people, exchanging information with people, employing surveys to collect information about community wishes, using newsletters, school newspapers and meetings to get information out into the community, and inviting parents and community groups into the school (Ryan, 2003).

Inclusion is best served in schools that emphasize student learning and teaching practice and strive to improve both the capacities and commitment of professional educators. The latter is best achieved when educators are aware of practices that work in diverse settings and are given the chance to talk critically about their teaching. Research is clear on the best ways of delivering curriculum in inclusive ways. For example, it has been found that students are generally included when the school honors different ways of knowing and sources of knowledge, allows students to write and speak in their own vernacular and employs culturally-compatible communication styles. Educators can promote inclusion in their classrooms when they express cultural solidarity with their students, demonstrate that they care about them and hold high expectations for all of them (Riehl, 2000). It is easier for teachers to adopt these practices in schools where 
goals are clearly understood, collaboration is supported, risk-taking is encouraged and monitoring of progress is fair. Inclusive teaching practice is best developed when teachers and their supervisors have opportunities to talk about it. Particularly effective are dialogues that encourage teachers to become aware of, and critically reflect on their learning and professional practices (Blasé \& Blasé, 2000). These critical conversations occur most often in contexts where school goals are developed collaboratively and clearly communicated to everyone. This is particularly important in diverse settings because members of various groups may not understand what others in more homogeneous contexts simply take for granted. It is also important for teachers to be clear about their goals for student achievement, their ability to meet them and their awareness of when goals are met. All this occurs most often in schools that spend time making sure that student learning is a priority (Kleine-Kracht, 1993).

For schools to be truly inclusive communities, they need to adopt inclusive policy-making processes. Policy deliberations can display inclusion in two ways. The first is by promoting policies that favor inclusive values. The second is by organizing policy deliberation processes that are themselves inclusive. This means that all interests in the school community have to be fairly represented in these processes and everyone must have equally fair opportunities to influence the outcome of these processes. In order to ensure that this happens, schools need to know and understand their communities; invite those who will fairly represent all segments of the community to participate; establish an appropriate place for deliberations; pay particular attention to the power dynamics and ensure that everyone is heard in these deliberations; help policy-makers see problems from others' viewpoints; consult with the people affected by the policy; and be 
prepared to engage in an on-going process of monitoring and adjusting the policies (Corson, 1996; Gillborn, 1995; Ryan, 2006).

Finally, if inclusion is to be successfully promoted in schools, then it has to become firmly entrenched in day-to-day activities (Gillborn, 1995; May, 1994; Ryan, 2003). To increase the prospects for success in these efforts, schools need to involve whole school communities. This entails making inclusion an essential and routine part of educational practice in ways that ensure its longevity and protect it against wider changes in educational policy. For schools to promote cultures that foster inclusion, they will have to acknowledge the complexities of culture and be sensitive to the ends to which their efforts are directed. An inclusive approach to leadership demands that the efforts of members of the school community should promote everyone's interests -- not just those of management or of dominant groups. School vision statements, for example, ought to emanate not only from management or powerful individuals and groups, but equitably from all segments of the school community. Whatever shared values emerge around whole-school efforts to incorporate inclusion must represent all groups and all groups must benefit equally from these values. Schools need to find ways to make space for traditionally excluded cultures to be part of this process. Their values, beliefs and lifestyles should be honored and incorporated into the content and process of schooling. Inclusive Leadership

Inclusive leadership is one of the promising approaches to leadership that allows us to work toward social justice in our schools and communities. But putting these and other similar approaches into place will not come easily. This is because there are many obstacles that can get in the way. These include a reluctance to recognize or acknowledge 
exclusive practices (Anderson, 1990; Ryan, 2003; Shields, 2003), increasing enthusiasm for exclusive measures of accountability (McNeil, 2000), managerial approaches that reinforce already entrenched hierarchies (Blackmore, 1999; Gewirtz, 2002), policies that place responsibility for what happens in organizations in the hands of single individuals like school administrators (Ryan, 2006), cynicism towards efforts to empower people (Anderson, 1990), and a culture that has a belief in heroes (Loeb, 1994). Despite such formidable obstacles, we need to press on, doing everything we can to overcome them. If we are genuinely interested in making the world a better place for humanity, then we can begin by putting inclusive leadership into practice in our schools. 


\section{References}

Anderson, G. (1990). Toward a critical constructivist approach to school administration: Invisibility, legitimation, and the study of non-events. Educational Administration Quarterly, 26(1), 38-39.

Bailey, J., \& du Plessis, D. (1997). Understanding principals' attitude toward inclusive schooling. Journal of Educational Administration, 35(5), 428-438.

Bennett, C. (2001). Genres of research in multicultural education. Review of Educational Research, 71(2), 171-217.

Bishop, A. (2002). Becoming an ally: Breaking the cycle of oppression in people. Halifax: Fernwood.

Blackmore, J. (1989). Educational leadership: A feminist critique and reconstruction. In J. Smith (Ed.), Critical perspectives on educational leadership (pp. 93 - 129). London: Falmer.

Blackmore, J. (1999). Troubling women. Buckingham: Open University Press.

Blasé, J., \& Anderson, G. (1995). The micropolitics of educational leadership: From control to empowerment. New York: Teachers College Press.

Blasé, J., \& Blasé, J. (2000). Principals’ perspectives on shared governance leadership. Journal of School Leadership, 10(1), 9-39.

Boscardin, M., \& Jacobson, S. (1997). The inclusive school: Integrating diversity and solidarity through community-based management. Journal of Educational Administration, 35(5), 466-476.

Brown, K. (2004). Leadership for social justice and equity: Weaving a transformative framework and pedagogy. Educational Administration Quarterly, 40(1), 77-108. 
Burbules, N. (1993). Dialogue in teaching: Theory and practice. New York: Teacher College Press.

Byrne, D. (1999). Social exclusion. Philadelphia: Open University Press.

Coleman, J. et al. (1966). Equality of educational opportunity. Washington D.C: Government Printing Office.

Coombs, C. (2002). Reflective practice: Developing habits of mind. Unpublished doctoral dissertation. Ontario Institute for Studies in Education/University of Toronto, Toronto.

Corson, D. (1993). Language, minority education and gender: Linking social justice and power. Clevedon: Multilingual Matters.

Corson, D. (1996). Emancipatory discursive practices. In K Leithwood, et al. (Ed.), International handbook of educational leadership and administration (pp. 10431067). Dordrecht: Kluwer.

Dantley, M. (2005). African American spirituality and Cornel West's notions of prophetic pragmatism: Restructuring educational leadership in American urban schools. Educational Administration Quarterly, 41(4), 651-674.

Datnow, A. (1998). The gender politics of educational change. London: Falmer Press.

Dei, G., James, I. M., Karumancherry, L. L., James-Wilson, S., \& Zine, J. (2000) Removing the margins: The challenges and possibilities of inclusive schooling. Toronto: Canadian Scholar's Press.

Education Quality and Accountability Office. (2002). Ontario secondary school literacy Test: Report of provincial results. Toronto: Queen's Printer for Ontario.

Evans, R. (1999). The pedagogic principal. Edmonton: Qual Institute Press. 
Foster, W. (1989). Toward a critical practice of leadership. In J. Smyth (Ed.), Critical perspectives on educational leadership (pp.70-81). London: Falmer.

Furman, G. \& Gruenewald, D. (2004). Expanding the landscape of social justice: A critical ecological analysis. Educational Administration Quarterly, 40(1), 47-76.

Gale, T. \& Densmore, K. (2003). Democratic educational leadership in contemporary times. International Journal of Leadership in Education, 6(2), 119-136.

Gewirtz, S. (2002). The managerial school: Post-welfarism and social justice in education. New York: Routledge.

Giles, C. \& Hargreaves, A. (2006). The sustainability of innovative schools as learning organizations and professional learning communities during standardized reform. Educational Administration Quarterly. 42(1).

Gillborn, D. (1995). Racism and antiracism in real schools. Philadelphia: Open University Press.

Grace, G. (1995). School leadership: Beyond educational management. London: Falmer. Grogan, M. (2002). Influences of the discourse of globalisation on mentoring for gender equity and social justice in educational leadership. Leading \& Managing, 8(2), 123134.

Gronn, P. ( 2002). Distributed leadership, In K. Leithwood \& P. Hallinger (Eds.), Second international handbook of educational leadership and administration (pp. 653-696). Dordrecht: Kluwer.

Grundy, S. (1993) Educational leadership as emancipatory praxis. In J. Blackmore \& J. Kenway (eds.). Gender matters in educational administration and policy (pp. 65-78). London: Falmer Press. 
Hargreaves, A. (in press). The carousel of leadership succession. Phi Delta Kappan.

Ingram, P., Mayrowetz, D., \& Weinstein, C. (1997). Sources of leadership for inclusive education: Creating schools for all children. Educational Administration Quarterly, 35(3), 423-449.

Jencks, C. (1972). Inequality: A reassessment of effect of family and schooling in America. New York: Basic Books.

Keys, M., Hanley-Maxwell, C. \& Capper, C. (1999). Spirituality? It is the core of my leadership: Empowering leadership in an inclusive elementary school. Educational Administration Quarterly, 35(2), 203-237.

Kleine-Kracht, P. (1993). Indirect instructional leadership: An administrator's choice. Educational Administration Quarterly, 29(2), 187-211.

Leithwood, K., Jantzi, D. \& Steinbach, R. (1999). Changing leadership for changing times. Buckingham: Open University Press.

Levine-Rasky, C. (1993). Listening as an appropriate response by members of privileged groups. Paper presented at CSAM meeting, Carleton University, Ottawa.

Loeb, M. (1994). Where leaders come from. Fortune (September), 41-42.

Lopez, G. (2003). The (racially neutral) politics of education: A Critical Race Theory perspective. Educational Administration Quarterly, 39(1), 68-94.

Lugg, C. (2003). Sissies, faggots, lezzies and dykes: Gender, sexual orientation, and a new politics of education. Educational Administration Quarterly, 39(1), 95-134.

Madanipour, G., Cars, G., \& Allen, J. (Eds.). (1998). Social exclusion in European cities. London: Jessica Kingsley. 
Marshall, C. (2004). Yes, “but”...education leaders discuss social justice. Journal of School Leadership, 14, 530-563.

Maxcy, S. (1998). Preparing school principals for ethno-democratic leadership. International Journal of Leadership in Education, 1(3), 217-235.

May, S. (1994). Making multicultural education work. Clevedon, UK: Multilingual Matters.

McNeil, L. M. (2000). Contradictions of school reform: Educational costs of standardized testing. New York: Routledge.

Munck, R. (2005). Globalization and social exclusion: A transformationalist perspective. Bloomfield, CT: Kumarian.

Natriello, J. et. al. (1990). Schooling disadvantaged children: Racing against catastrophe. New York: Teachers College Press.

Oakes, J. \& Lipton, M. (2002). Struggling for educational equity in diverse communities: School reform as social movement. Journal of Educational Change, 3(4), 383-406.

Ogbu, J. (1994). Racial stratification and education in the United States: Why inequality persists. Teacher College Record, 96, 264-271.

Orenstein, P. (2002). Striking back: Sexual harassment at Weston. In S. Bailey (Ed.), The Jossey-Bass Reader on Gender in Education (pp. 459-475). San Francisco: JosseyBass.

Organization for Economic Cooperation and Development (OEDC). (2005). First results from PISA 2003. OECD. Accessible from http://www.oecd.org

Ozga, J. (1993). Women in educational management. Milton Keynes: Open University Press. 
Paquette, J. (1990) Minority participation in secondary education: A fine-gained descriptive methodology. Education Evaluation and Policy Analysis, 13(2), 139-158.

Pounder, D., Ogawa, R., \& Adams, E. (1995). Leadership as an organization-wide phenomenon: Its impact on school performance. Educational Administration Quarterly, 31(4), 564-588.

Rawls, J. (1972). A theory of justice. Oxford: Oxford University Press.

Riehl, C. (2000). The principal's role in creating inclusive schools for diverse students: A review of normative, empirical, and critical literature on the practice of educational administration. Review of Educational Research, 70(1), 55-82.

Riley, E.K. \& Rustique-Forester, E. (2002). Working with disaffected students. London: Paul Chapman.

Ryan, J. (1988). Conservative science in educational administration. Journal of Educational Administration and Foundations, 3(2), 5-22.

Ryan, J. (1991). Observing and normalizing: Foucault, discipline, and inequality in schooling. Journal of Educational Thought, 25(2), 104-119.

Ryan, J. (2003). Leading diverse schools. Dordrecht: Kluwer.

Ryan, J. (2006). Inclusive leadership. San Francisco: Jossey-Bass.

Sears, J.(1993). Responding to the sexual diversity of faculty and students: Sexual praxis and the critical reflective administrator. In C. Capper (ed.), Educational administration in a pluralistic society (pp.110-172). Albany: SUNY Press.

Senge, P. (1990) The fifth discipline: The art and practice of learning organization. Toronto: Doubleday. 
Shapiro, J. Sewell, T. \& Ducette, J. (2001). Reframing diversity in education. Lanham, Maryland: Scarecrow.

Shields, C. (2003). Good intentions are not enough: Transformative leadership for communities of difference. Lanham, MD: Scarecrow Press.

Smylie, M., Conley, S. \& Marks, H. ( 2002). Building leadership into the roles of teachers. In J. Murphy (Ed.), Educational leadership challenge: Redefining leadership for the $21^{\text {st }}$ Century (pp: 162-188). Chicago: NSSE.

Smyth, J. (1989). A “pedagogical” and "educative” view of leadership. In J. Smyth (Ed.), Critical perspectives in educational leadership (pp. 179-204). London: Falmer Press.

Spillane, J. P., \& Orlina, E. C. (2005). Investigating leadership practice: Exploring the entailments of taking a distributed perspective. Leadership and Policy in Schools, $4(4), 157-176$.

Stein, N. (2002). Bullying as sexual harassment in elementary schools. In S. Bailey (Ed.), The Jossey-Bass Reader on Gender Education (pp. 409-428). San Francisco: JosseyBass.

Thousand, J. \& Villa, R. (1994). Managing complex change toward inclusive schooling. In R. Villa \& J. Thousand (Eds.), Creating an inclusive school (pp. 5-79). Alexandra, VA: Association for Supervision and Curriculum Development.

Walker, A \& Walker, C. (1997) (Ed.) Britain divided: The growth of social exclusion in the 1980s and 1990s. London: Child Poverty Action Group.

Woods, P. (2005). Democratic leadership in education. Thousand Oaks, CA: Sage. Young, I. R. (1999). Deliberative politics: Essays on democracy and disagreement. Oxford: Oxford University Press. 